\title{
An in vitro study on the regulation of oxidative protective genes in human gingival and intestinal epithelial cells after treatment with salmon protein hydrolysate peptides
}

\author{
Bomi Framroze$^{1}$, Freddy Havaldar ${ }^{2}$, Shashi Misal ${ }^{3}$
}

${ }^{1}$ Hofseth Biocare AS, Havnegata 11, Aalesund, Norway; ${ }^{2}$ St. Xaviers College, Department of Chemistry, Mumbai 400001, India; ${ }^{3} \mathrm{GPH}$ Biotech LLC, 1455 Adams Drive, Menlo Park, CA 94025, USA

Corresponding author Bomi Framroze, Hofseth Biocare AS, Havnegata 11, Aalesund, Norway

Submission Date: June $5^{\text {th }}$, 2018, Acceptance Date: August 28 ${ }^{\text {th }}$, 2018, Publication Date: August $30^{\text {th }}, 2018$

Citation: Framroze B., Havaldar F., Misal S. An invitro study on the regulation of oxidative protective genes in human gingival and intestinal epithelial cells after treatment with salmon protein hydrolysate peptides. Functional Foods in Health and Disease 2018; 8(8):398-411. DOI: https://doi.org/10.31989/ffhd.v8i8.529

\begin{abstract}
Background: Under physiological conditions, molecular oxygen generates reactive oxygen species (ROS) as metabolic by-products. In the absence of an adequate defense mechanism, the accumulation of ROS leads to cell membrane and DNA damage, in addition to tissue degeneration. The up/down regulation of one or more oxidative stress-related genes is one mechanism which confers cytoprotection to tissues exposed to oxidative injury.
\end{abstract}

Objective: To measure the up/down regulation of 84 oxidative protective NRF2 genes within primary human gingival epithelial cells (HGEPp) and human intestinal epithelial cells (HIEC-6) when treated with varying concentrations of salmon protein hydrolysate (SPH) solution.

Methods: We measured up/down regulation of 84 oxidative protective genes in primary human gingival epithelial pooled cells and human intestinal epithelial cells after pretreatment with 25 , 50, and $100 \mu \mathrm{M} / \mathrm{ml}$ of salmon protein hydrolysate solution. A human $\mathrm{RT}^{2}$ Profiler PCR array was used to evaluate the relative change in the expression of these common oxidative protective genes. The salmon protein hydrolysate contains a mixture of bioactive peptides, resulting from enzyme hydrolysis of salmon head and backbones.

Results: Treatment with salmon protein hydrolysate peptides demonstrated up-regulation for 16 human oxidative protective genes and down-regulation for 9 human oxidative stress-related 
genes. Three genes (ferritin heavy polypeptide-1 (FTH1), heme oxygenase-1 (HMOX1), and arachidonate 12-lipoxygenase (ALOX12)) showed regulation changes at physiologically applicable levels.

Conclusion: The improved oxidation protection observed after SPH treatment conferred by HMOX1 / ALOX12 regulation to HGEPp and HIEC-6 cells may find ultimate utility for these bioactive peptides in the modulation of gastrointestinal stress in irritable bowel syndrome and enterocolitis.

\section{BACKGROUND}

The up/down regulation of one or more oxidative stress-related genes is the subject of investigation by many researchers as a possible mechanism that can confer cytoprotection to tissues exposed to oxidative injury. While molecular oxygen is essential for the survival of almost all eukaryotes, its processing under physiological conditions generates reactive oxygen species (ROS) such as hydrogen peroxide, superoxide, peroxynitrite, and hydroxyl radicals, as metabolic by-products. In the absence of an adequate defense mechanism, the accumulation of ROS and electrophiles leads to cell membrane and DNA damage, mutagenicity, degeneration of tissues, premature aging, apoptotic cell death, and cancers $[1,2,3]$.

To combat this oxidative stress, mammalian cells have developed an array of inducible defensive gene activations which results in a neutralization of the oxidative stress events, reduced ROS, and thereby increased cell survival $[4,5]$. The cellular antioxidant defense mechanism employs a number of enzymes and small organic antioxidants such as Vitamins $\mathrm{C}$ and $\mathrm{E}$ to keep ROS at reduced levels, which are not critical to the organism's survival.

Enzymes with antioxidant properties, capable of inactivating ROS and preventing ROSinitiated reactions include superoxide dismutase, catalase, and glutathione peroxidase. They belong to the group referred to as "direct" Phase 1 antioxidant enzymes $[6,7,8]$.

Phase 2 detoxifying (conjugating) enzymes are classified as "indirect" antioxidants based on their role in maintaining redox balance and thiol homeostasis. They contribute to biosynthesis, recycling of thiols, and facilitating of the excretion of oxidized, reactive secondary metabolites (quinones, epoxides, aldehydes, and peroxides) through reduction/conjugation reactions during the process of xenobiotic detoxification [9]. Phase 2 enzymes with antioxidant capability include glutathione S-transferase isozymes and NADP(H): quinine oxidoreductase (NQO1), glutamyl cysteine ligase (GCLC), and UDP-glucuronosyltransferase (UGT).

The signal transduction pathways responsible for sensing oxidative stress and activating the appropriate defense genes are still not completely understood in mammals. The transcription factor Nrf2, which is activated by ROS, appears to be a key regulator in oxidative stress gene regulation. Nrf2 is a member of the Cap'n'Collar family of bZIP proteins and recognizes the antioxidant response element (ARE) in the promotion of its over 2000 target genes [10]. Under normal basal conditions, Nrf2 is bound to its inhibitor, the cytoskeleton-associated protein Keap1, which represses Nrf2 by facilitating its proteasomal degradation [11]. Upon treatment by antioxidants, Nrf2 is released from Keap1 and is translocated into the nucleus. This process is followed by 
hetero-dimerization with other transcription factors, such as Jun and small Maf $[12,13,14]$ that initiates up-regulation of antioxidant genes.

Invitro gene expression has been used to understand the role of antioxidants in many diseases. Gene expression was used to show 200 differentially expressed oxidative genes in subjects with COPD when compared with healthy smokers; significant changes in oxidant response genes observed in vivo were reproduced invitro using primary bronchial epithelial cells from the same donors [15]. Invitro gene expression has also been studied in human corneal endothelial cells (HCECs) to see if nuclear oxidative DNA damage increases with age and whether HCECs respond to this damage by upregulating their expression of oxidative stress and DNA damage-signaling genes in an age-dependent manner [16]. Four of 84 genes demonstrated a statistically significant age-related difference in the expression of oxidative stress-related genes.

Studies have shown that diet can also play a role in the regulation of oxidative protective genes. A recent study aiming to identify molecular markers of diet-related diseases in response to food evaluated peripheral blood mononuclear cells (PBMC) as a model invitro system as a readily available source of RNA to discern gene expression signatures in relation to personalized obesity treatment. PBMC were collected from obese men before and after an 8-week low-calorie diet (LCD) to lose weight. Changes in gene expression before and after the LCD were validated by qRT-PCR and demonstrated a decrease in some specific oxidative stress and inflammation genes, such as apolipoprotein 1 (APOL1) and NF-kB repression factor (NFKB) [17].

As stated, the objective of this study focuses on primary human gingival epithelial cells (HGEPp) and human intestinal epithelial cells (HIEC-6). These two cells lines, when treated with varying concentrations of salmon protein hydrolysate $(\mathrm{SPH})$ solution, were selected as in-vitro representatives of the GI tract similar to the bronchial epithelial cells used by Pierrou et al in COPD. As the major site of first entry for xenobiotics, the oral cavity and gastrointestinal tract are continuously exposed to a broad array of compounds with ROS capability. Further mucosal metabolism can lead to metabolites with increased toxicity, increasing the susceptibility of the oral cavity and gastrointestinal tract to oxidative metabolites, chemical toxicity, and potential necrotizing colitis.

SPH contains a multitude of bioactive peptides. The results of this study will be used to guide the development of a functional food which confers a protective effect on the gastrointestinal tract and that can be used in conjunction with medical treatment in the control of Inflammatory Bowel Disease (IBD), such as ulcerative colitis and Crohn's disease.

\section{METHODS AND MATERIALS}

\section{Chemicals and Reagents}

Salmon Protein Hydrolysate Powder was procured from Hofseth Biocare AS, Norway as a light yellow free flowing powder supplied as Batch No. 17-006. HGEPp cells were purchased from Cell-n-Tec Advanced Cell Systems AG and HIEC-6 cells were purchased from the ATCC, USA. The RNEasy Plus Micro Kit, RNase-free DNase Set, RT ${ }^{2}$ Easy First Strand Kit (DNA generator) and $\mathrm{RT}^{2} \mathrm{SYBR}^{\circledR}$ Green fluor qPCR master-mix were purchased from Qiagen N.V., USA. Oxidative Stress RT ${ }^{2}$ profiler PCR arrays (84 protective genes) were purchased from Qiagen N.V., USA. The iCycler PCR system from Bio-Rad Inc., USA was used for the RT-PCR. 


\section{Cell Cultures}

Pooled primary HGEPp cells were propagated in CnT-Prime epithelial culture medium provided by Cell-n-Tec on $100 \mathrm{~mm}$ petri dishes coated with $30 \mathrm{mg} / \mathrm{ml}$ Type I rat tail collagen (BD Biosciences) diluted in Dulbecco's phosphate-buffered saline in a 1:5 ratio (DPBS). This cell type was chosen since SPH has been studied as an oral solution formulation in patients, which puts this cell type in close contact with HGEPp cells. Our previous studies with HGEPp cells and other active peptides have shown positive results at $2.5 \times 10^{4}$ cells $/ \mathrm{cm}^{2}$ density to grow cell monolayers and acclimated overnight at $37^{\circ} \mathrm{C}$. For this assay, we grew the HGEPp cells in $4 \times 60 \mathrm{~mm}$ Nunc ${ }^{\mathrm{TM}}$ Cell Culture dishes at the same $2.5 \times 10^{4}$ cells $/ \mathrm{cm}^{2}$ density concentration.

HIEC-6 (ATCC CRL-3266) cells were propagated in OptiMEM 1 reduced serum medium (Gibco Catalog No. 31985) with 20 mM HEPES, 10 mM GlutaMAX, 10 ng/ml Epidermal Growth Factor (EGF), and fetal bovine serum at a final concentration of $4 \%$ on $100 \mathrm{~mm}$ petri dishes. This cell type was chosen since SPH has been studied as a GI health modulator. Our previous studies with HIEC- 6 cells and other active peptides have shown positive results at $1 \times 10^{5}$ cells $/ \mathrm{cm}^{2}$ density to grow cell monolayers and acclimated overnight at $37^{\circ} \mathrm{C}$. For this assay, we grew the HIEC-6 cells in 4 x $60 \mathrm{~mm}$ Nunc ${ }^{\mathrm{TM}}$ Cell Culture dishes at the same $1 \times 10^{5}$ cells $/ \mathrm{cm}^{2}$ density concentration.

\section{Preparation of SPH Dosing solutions}

SPH (Batch \#17006) was received as a powder from Hofseth Biocare AS and a $100 \mathrm{mM}$ DMSO stock suspension was prepared.

Further dilutions were prepared in DMSO from the $100 \mathrm{mM}$ DMSO stock and the DMSO dilution was then added into $10 \mathrm{~mL}$ of Dulbecco's phosphate-buffered saline to arrive at final concentrations of 25,50 , and $100 \mu \mathrm{M} / \mathrm{ml}$ of SPH.

All dosing solutions contained $0.3 \%$ of DMSO which is below the maximum tolerated DMSO concentration of $0.8 \%$ for HGEPp and HIEC-6 cells.

\section{Pre-Treatment of HGEPp \& HIEC-6 cells with SPH solutions and DMSO blank}

Dish cell concentrations were selected to be $2.5 \times 10^{5} / \mathrm{ml}$ to yield an OD absorbance within the linear portion of the control curve for both cells lines. Once the cells were cultured and ready on the dishes, the media was removed and discarded. The cells were washed gently with DPBS 2-3 times and the last wash removed and discarded. Six HGEPp and HIEC-6 cell culture dishes were then pretreated for $24 \mathrm{~h}$ with SPH at 25,50 , and $100 \mu \mathrm{g} / \mathrm{mL}$ concentrations (in duplicate) at $37^{\circ} \mathrm{C}$. One cell culture dish for each cell line was pretreated for $24 \mathrm{~h}$ with the DMSO blank solution at $37^{\circ} \mathrm{C}$.

\section{mRNA preparation from cells}

The RNeasy UCP Micro Kit was used to purify mRNA from both HGEPp and HIEC-6 treated cells.

After discarding and washing treatments, the cells were pelleted by centrifugation for 5 min at 1000 RPM in a centrifuge tube. All the supernatant was carefully removed by aspiration, making sure all the cell medium has been removed thoroughly. The cells were disrupted by adding $350 \mu 1$ buffer RULT in order to loosen the cell pellet from the tube and then vortexed to mix thoroughly. 
Next, the mixture was homogenized by being passed through the lysate 5 times through 20-gauge needle fitted to an RNase-free syringe. $350 \mu \mathrm{l}$ of $70 \%$ ethanol was added to the lysate and mixed again by pipetting. Then the sample was transferred, including any precipitate that may have formed, to an RNeasy UCP MinElute spin column placed in a $2 \mathrm{ml}$ collection tube and centrifuged for $15 \mathrm{~s}$ at 10,000 rpm. The flow thru was discarded. $350 \mu \mathrm{l}$ Buffer RUWT was added to the spin column and centrifuged for $15 \mathrm{~s}$ at 10,000 rpm to wash the membrane. The flow thru was discarded. $10 \mu \mathrm{l}$ DNase I stock solution was added to $70 \mu \mathrm{l}$ Buffered RDD. After being mixed gently, 80ul of the DNase I mix was added directly to the spin-column membrane and vortexed for $15 \mathrm{~min} .350$ $\mu 1$ Buffer RUWT was added to the spin column and centrifuged for $15 \mathrm{~s}$ at 10,000 rpm to wash it and the flow thru was discarded. The spin column was placed in a new 2 ml collection tube. 500 $\mu l$ Buffer RUPE was added and centrifuged for $15 \mathrm{~s}$ at 10,000 rpm. The flow thru was discarded. The spin column was washed again with $500 \mu \mathrm{l}$ of $80 \%$ ethanol and placed in a new $2 \mathrm{ml}$ collection tube and centrifuge for $5 \mathrm{~min}$ at full speed with the lid open to make sure all ethanol is removed. The spin column was placed in a new $1.5 \mathrm{ml}$ collection tube, $14 \mu \mathrm{l}$ ultra-clean water was added directly to the center of the spin-column membrane, and the lid was closed and centrifuged for 1 min at full speed to elute the RNA. The dead volume of the spin column is $4 \mu$ l. Eluted with $16 \mu l$ ultra-clean water to yield a $20 \mu \mathrm{l}(4 \mu \mathrm{g})$ RNA eluate.

\section{cDNA prep for $R T-P C R$}

A RNA sample from each of the above seven treatments was added to $40 \mu$ of Buffer GE2 (gDNA elimination buffer) and RNase-free $\mathrm{H} 2 \mathrm{O}$ to make a final volume of $60 \mu \mathrm{l}$. The sample was incubated at $37^{\circ} \mathrm{C}$ for $5 \mathrm{~min}$ and immediately placed on ice for 2 minutes. $62 \mu \mathrm{l}$ of the BC5 Reverse Transcriptase Mix was added to each $60 \mu 1$ RNA sample for a final volume of $102 \mu$. The sample was then incubated at $42^{\circ} \mathrm{C}$ for exactly 15 minutes and then the reaction was immediately stopped through being heating at $95^{\circ} \mathrm{C}$ for 5 minutes. Sample was then ready for PCR.

\section{Human Oxidative Stress $\boldsymbol{R T}^{2}$ Profiler PCR Array}

RT-PCR is a highly sensitive and reliable method for gene expression analysis. The assay was used to analyze expression levels of 84 genes related to oxidative stress in HIEC-6 cells pre-treated with SPH at 25,50 , and $100 \mu \mathrm{g} / \mathrm{ml}$ for $24 \mathrm{~h}$. The cDNA from above was mixed with the $\mathrm{RT}^{2} \mathrm{SYBR}$ Green fluor Mastermix and aliquoted into the wells of the $\mathrm{RT}^{2}$ Profiler PCR Array shown below. RT-PCR was performed on an iCycler. Gene expression was compared using $\mathrm{Ct}$ values and the results were calculated using $\Delta \Delta \mathrm{Ct}$ method with normalization to the average expression levels of the five common genes (ACTB, B2M, GAPDH, HPRT, and RPL13A)

The selection of the 96 well array of test genes and housekeeping genes are shown below.

\section{ANTIOXIDANTS}

Glutathione peroxidases (GPx):

GPX1, GPX2, GPX3, GPX4, GPX5, GPX6, GPX7, GSTP1, GSTZ1.

Peroxiredoxins (TPX): PRDX1, PRDX2, PRDX3, PRDX4, PRDX5, PRDX6.

Other peroxidases: 
CAT, CYBB, CYGB, DUOX1, DUOX2, EPX, LPO, MGST3, MPO, PTGS1 (COX1), PTGS2 (COX2), PXDN, TPO, TTN.

Other antioxidants:

ALB, APOE, GSR, MT3, SOD1, SOD3, SRXN1, TXNRD1, TXNRD2, VIMP.

REACTIVE OXYGEN SPECIES (ROS) METABOLISM

Superoxide dismutases (SOD): SOD1, SOD2, SOD3.

Other superoxide metabolism genes:

ALOX12, CCS, DUOX1, DUOX2, GTF2I, MT3, NCF1, NCF2, NOS2, NOX4, NOX5, PREX1, UCP2.

Other Reactive Oxygen Species (ROS) metabolism genes:

AOX1, BNIP3, EPHX2, MPV17, SFTPD.

Oxidative stress responsive genes:

APOE, ATOX1, CAT, CCL5, CYGB, DHCR24, DUOX1, DUOX2, DUSP1, EPX, FOXM1, FT H1, GCLC, GCLM, GPX1, GPX2, GPX3, GPX4, GPX5, GPX6, GPX7, GSR, GSS, HMOX1, H SPA1A, KRT1, LPO, MBL2, MPO, MSRA, NQO1, NUDT1, OXR1, OXSR1, PDLIM1, PNKP, PRDX2, PRDX5, PRDX6, PRNP, RNF7, SCARA3, SEPP1, SIRT2, SOD1, SOD2, SQSTM1, S RXN1, STK25, TPO, TTN, TXN, TXNRD1, TXNRD2, VIMP OXYGEN TRANSPORTERS CYGB, MB

The genomic DNA control (GDC) specifically detects non-transcribed genomic DNA contamination with a high level of sensitivity. The reverse-transcription control (RTC) tests the efficiency of the reverse-transcription reaction performed with the $\mathrm{RT}^{2}$ First Strand Kit by detecting template synthesized from the kit's built-in external RNA control. The positive PCR control (PPC) consists of a pre-dispensed artificial DNA sequence and the assay that detects it so that the efficiency of the polymerase chain reaction is quantified and the controls are in replicates to ensure intra-plate consistency.

\section{RESULTS}

\section{Upregulated oxidative stress genes}

Treatment of HGEPp cells with SPH demonstrated up-regulation with a Fold Change greater than two for sixteen human oxidative stress-related genes-APOE, CYGB, EPX, FTH1, GCLC, GPX1, GSR, GSTZ1, HMOX1, MBL2, MSRA, NOS2, NQO1, PRDX5, SELS, SOD1. In contrast, treatment of HIEC-6 cells with SPH demonstrated up-regulation with a Fold Change greater than two for eleven human oxidative stress-related genes - APOE, EPX, FTH1, GCLC, GSS, HMOX1, MBL2, NOS2, NQO1, PRDX5, SOD1 at the $100 \mu \mathrm{M} / \mathrm{ml} \mathrm{SPH} \mathrm{concentration} \mathrm{(Table} 1 \& 2$ ). The DMSO blank treatments did not show any change in regulation for any gene in the array. Ten genes showed common upregulation in both cell lines - APOE, EPX, FTH1, GCLC, HMOX1, MBL2, NOS2, NQO1, PRDX5, SOD1. 
Table 1. Upregulated oxidative stress-related genes in HGEPp cells following SPH treatment

\begin{tabular}{|c|c|c|c|c|}
\hline GeneBank & Symbol & Description & $\begin{array}{l}\text { Fold } \\
\text { Change }\end{array}$ & $P$ value \\
\hline NM_000041 & APOE & Apolipoprotein $\mathrm{E}$ & 2.76 & 0.028 \\
\hline NM_134268 & CYGB & Cytoglobin & 2.59 & 0.041 \\
\hline NM_000502 & EPX & Eosinophil peroxidase & 3.05 & 0.037 \\
\hline NM_002032 & FTH1 & Ferritin, heavy polypeptide 1 & 4.82 & 0.033 \\
\hline NM_001498 & GCLC & Glutamine-cysteine ligase cat. sub. & 4.91 & 0.016 \\
\hline NM_000581 & GPX1 & Glutathione peroxidase 1 & 2.88 & 0.034 \\
\hline NM_000178 & GSS & Glutathione synthetase & 2.63 & 0.011 \\
\hline NM_001513 & GSTZ1 & Glutathione transferase zeta 1 & 2.49 & 0.045 \\
\hline NM_002133 & HMOX1 & Heme oxygenase (decycling) 1 & 5.63 & 0.017 \\
\hline NM_000250 & MBL2 & Mannose binding lectin 2 & 2.42 & 0.028 \\
\hline NM_012331 & MSRA & Methionine sulfoxide reductase A & 2.07 & 0.034 \\
\hline NM_000625 & NOS2 & Nitric oxide synthase 2 & 2.76 & 0.026 \\
\hline NM_000903 & NQO1 & $\mathrm{NAD}(\mathrm{P}) \mathrm{H}$ dehydrogenase quinone 1 & 3.85 & 0.019 \\
\hline NM_181652 & PRDX5 & Peroxiredoxin 5 & 2.74 & 0.039 \\
\hline NM_203472 & SELS & Selenoprotein S & 2.26 & 0.042 \\
\hline NM_000454 & SOD1 & Superoxide dismutase 1 & 3.50 & 0.013 \\
\hline
\end{tabular}


Table 2. Up regulated oxidative stress-related genes in HIEC-6 cells following SPH treatment

\begin{tabular}{|c|c|c|c|c|}
\hline GenBank & Symbol & Description & $\begin{array}{l}\text { Fold } \\
\text { Change }\end{array}$ & $\begin{array}{l}\mathrm{P} \\
\text { Value }\end{array}$ \\
\hline NM_000041 & APOE & Apolipoprotein E & 5.43 & 0.037 \\
\hline NM_000502 & EPX & Eosinophil peroxidase & 2.79 & 0.022 \\
\hline NM_002032 & FTH1 & Ferritin, heavy polypeptide 1 & 4.25 & 0.039 \\
\hline NM_001498 & GCLC & Glutamine-cysteine ligase cat. sub. & 3.16 & 0.034 \\
\hline NM_000178 & GSS & Glutathione synthetase & 2.99 & 0.020 \\
\hline NM_002133 & HMOX1 & Heme oxygenase (decycling) 1 & 6.24 & 0.012 \\
\hline NM_000250 & MBL2 & Mannose binding lectin 2 & 3.57 & 0.033 \\
\hline NM_000625 & NOS2 & Nitric oxide synthase 2 & 2.48 & 0.041 \\
\hline NM_000903 & NQO1 & NAD(P)H dehydrogenase quinone 1 & 3.30 & 0.029 \\
\hline NM_181652 & PRDX5 & Peroxiredoxin 5 & 2.52 & 0.025 \\
\hline NM_000454 & SOD1 & Superoxide dismutase 1 & 3.99 & 0.038 \\
\hline
\end{tabular}

\section{Downregulated oxidative stress genes}

Treatment of HGEPp cells with SPH demonstrated downregulation with a Fold Change less than $50 \%$ for nine human oxidative stress-related gene -ALOX12, EPHX2, MGST3, MPO, NCF1, NOX5, PRDX1, PTGS2, SRXN1. In contrast, treatment of HIEC-6 cells with SPH demonstrated downregulation with a Fold Change less than $50 \%$ for seven human oxidative stress-related genes (ALOX12, MGST3, MPO, NCF1, NOX5, PTGS2, SRXN1) at the $100 \mu \mathrm{M} / \mathrm{ml} \mathrm{SPH}$ concentration (Tables $3 \& 4$ ). Seven common genes revealed downregulation in both cell lines ALOX12, MGST3, MPO, NCF1, NOX5, PTGS2, SRXN1. 
Table 3. Downregulated oxidative stress-related genes in HGEPp cells following SPH treatment

\begin{tabular}{|l|l|l|l|l|}
\hline GenBank & Symbol & Description & $\begin{array}{l}\text { Fold } \\
\text { Change }\end{array}$ & $\begin{array}{l}\text { P } \\
\text { Value }\end{array}$ \\
\hline NM_000697 & ALOX12 & Arachidonate 12-lipoxygenase & 0.29 & 0.040 \\
\hline NM_001979 & EPHX2 & Epoxide hydrolase 2 & 0.38 & 0.022 \\
\hline NM_004528 & MGST3 & Microsomal glutathione S-transferase 3 & 0.46 & 0.031 \\
\hline NM_000250 & MPO & Myeloperoxidase & 0.37 & 0.046 \\
\hline NM_000265 & NCF1 & Neutrophil cytosolic factor 1 & 0.43 & 0.015 \\
\hline NM_016931 & NOX5 & NADPH oxidase, Ca binding domain 5 & 0.41 & 0.023 \\
\hline NM_002574 & PRDX1 & Peroxiredoxin 1 & 0.40 & 0.034 \\
\hline NM_000963 & PTGS2 & Prostaglandin endoperoxide synthase 2 & 0.35 & 0.027 \\
\hline NM_080725 & SRXN1 & Sulfiredoxin 1 & 0.42 & 0.038 \\
\hline
\end{tabular}

Table 4. Downregulated oxidative stress-related genes in HIEC-6 cells following SPH treatment

\begin{tabular}{|c|c|c|c|c|}
\hline GenBank & Symbol & Description & $\begin{array}{l}\text { Fold } \\
\text { Change }\end{array}$ & $\begin{array}{l}\mathrm{P} \\
\text { Value }\end{array}$ \\
\hline NM_000697 & ALOX12 & Arachidonate 12-lipoxygenase & 0.17 & 0.023 \\
\hline NM_004528 & MGST3 & Microsomal glutathione S-transferase 3 & 0.38 & 0.044 \\
\hline NM_000250 & MPO & Myeloperoxidase & 0.29 & 0.035 \\
\hline NM_000265 & NCF1 & Neutrophil cytosolic factor 1 & 0.40 & 0.019 \\
\hline NM_016931 & NOX5 & NADPH oxidase, $\mathrm{Ca}$ binding domain 5 & 0.35 & 0.028 \\
\hline NM_000963 & PTGS2 & Prostaglandin endoperoxide synthase 2 & 0.41 & 0.016 \\
\hline NM_080725 & SRXN1 & Sulfiredoxin 1 & 0.34 & 0.022 \\
\hline
\end{tabular}




\section{Dose dependent response genes}

Additionally, two upregulated genes, FTH1 and HMOX1 in HGEPp cells and three upregulated genes, APOE, FTH1 and HMOX1 in HIEC-6 cells showed a dose-dependent result at the two lower doses of 25 and $50 \mu \mathrm{M} / \mathrm{ml}$ of SPH treatment. The ALOX12 gene showed a dose dependent downregulation in both HGEP and HIEC-6 cells (Table 5). None of the other genes showed a greater than two-fold change in upregulation nor a less than $50 \%$ change in down-regulation, when the SPH concentration was reduced to 50 and $25 \mu \mathrm{M} / \mathrm{ml}$.

Table 5. SPH dose-dependent gene regulation in both HGEP and HIEC-6 cells

\begin{tabular}{|c|c|c|c|c|c|}
\hline \multicolumn{6}{|c|}{ Fold Change at SPH concentrations of: } \\
\hline Genebank & Gene & Description & $\begin{array}{l}25 \\
\mu \mathrm{M} / \mathrm{ml}\end{array}$ & $\begin{array}{l}50 \\
\mu \mathrm{M} / \mathrm{ml}\end{array}$ & $\begin{array}{l}100 \\
\mu \mathrm{M} / \mathrm{ml}\end{array}$ \\
\hline \multicolumn{6}{|l|}{ HGEP Cells } \\
\hline $\begin{array}{l}\text { NM_002032 } \\
\text { P value }\end{array}$ & FTH1 & Ferritin, heavy polypeptide & $\begin{array}{l}2.10 \\
0.036\end{array}$ & $\begin{array}{l}2.96 \\
0.045\end{array}$ & $\begin{array}{l}4.82 \\
0.033\end{array}$ \\
\hline $\begin{array}{l}\text { NM_002133 } \\
\text { P value }\end{array}$ & HMOX1 & Heme oxygenase (decycling) 1 & $\begin{array}{l}1.92 \\
0.040\end{array}$ & $\begin{array}{l}3.47 \\
0.021\end{array}$ & $\begin{array}{l}5.63 \\
0.017\end{array}$ \\
\hline $\begin{array}{l}\text { NM_000697 } \\
\text { P value }\end{array}$ & ALOX12 & Arachidonate 12-lipoxygenase & $\begin{array}{l}0.49 \\
0.065\end{array}$ & $\begin{array}{l}0.37 \\
0.062\end{array}$ & $\begin{array}{l}0.29 \\
0.040\end{array}$ \\
\hline \multicolumn{6}{|l|}{ HIEC-6 Cells } \\
\hline $\begin{array}{l}\text { NM_000041 } \\
\text { P value }\end{array}$ & APOE & Apolipoprotein E & $\begin{array}{l}2.20 \\
0.027\end{array}$ & $\begin{array}{l}3.12 \\
0.018\end{array}$ & $\begin{array}{l}5.43 \\
0.037\end{array}$ \\
\hline $\begin{array}{l}\text { NM_002032 } \\
\text { P value }\end{array}$ & FTH1 & Ferritin, heavy polypeptide & $\begin{array}{l}1.98 \\
0.039\end{array}$ & $\begin{array}{l}2.83 \\
0.032\end{array}$ & $\begin{array}{l}4.25 \\
0.039\end{array}$ \\
\hline $\begin{array}{l}\text { NM_002133 } \\
\text { P value }\end{array}$ & HMOX1 & Heme oxygenase (decycling) 1 & $\begin{array}{l}2.85 \\
0.027\end{array}$ & $\begin{array}{l}3.93 \\
0.018\end{array}$ & $\begin{array}{l}6.24 \\
0.012\end{array}$ \\
\hline $\begin{array}{l}\text { NM_000697 } \\
\text { P value }\end{array}$ & ALOX12 & Arachidonate 12-lipoxygenase & $\begin{array}{l}0.41 \\
0.047\end{array}$ & $\begin{array}{l}0.28 \\
0.034\end{array}$ & $\begin{array}{l}0.17 \\
0.023\end{array}$ \\
\hline
\end{tabular}

\section{DISCUSSION}

Changes in regulation of oxidative genes has been implicated in GI tract diseases. The NOS1, IL1b, and HTR3a colonic mucosal genes have been shown to be involved in the pathogenesis of Irritable bowel syndrome with regulation of colon function [18]. Berberat et al. have demonstrated how heightened HO-1 expression or administration of biliverdin ameliorates dextran sodium sulfate-induced experimental colitis [19]. Cousins et al. have shown that mammalian nutritional status can affect the homeostatic balance of multiple physiological processes and their associated 
gene expression [20]. Food intake has specifically been shown to modulate gene expression, particularly within the GI tract. Ismail et al have described the effect of germinated brown rice on the expression of the peroxisome proliferator-activated receptor gamma gene [21]. Down regulation of the $P P A R \gamma$ gene likely contributes to germinated brown rice's antiobesity effects.

\section{FTH1 and HMOX1 gene upregulation}

Iron is required for normal cell growth and proliferation. However, excess iron is potentially harmful, as it can catalyze the formation of toxic reactive oxygen species (ROS). Thus, cells have evolved highly regulated mechanisms for controlling intracellular iron levels. Chief among these is the sequestration of iron. The FTH1 gene encodes the heavy subunit of ferritin, the major intracellular iron storage protein in humans, which sequesters free iron in a soluble and nontoxic state from dietary sources of iron. Previous studies have shown that increased synthesis of both subunits of ferritin occurs when exposed to oxidative stress [22]. Ferritin H or L overexpression reduced the accumulation of ROS in response to an oxidant challenge.

Our results demonstrate that up regulation of FTH1 do not solely need to be in response to an oxidant challenge and may be induced by specific activator peptides formed upon digestion of consumed food. SPH has been shown to increase circulatory ferritin levels in situationally anemic women [23]. This gene assay result indicates a possible mechanism for the observed increase in serum ferritin as being a direct up-regulation of the FTH1 gene producing more ferritin and thereby increasing overall iron in the serum.

HMOX1 gene expression is similarly induced by oxidative stress and seems to confer cytoprotection. The resultant HO1 enzyme catalyzes the degradation of heme, which produces biliverdin, ferrous iron, and carbon monoxide. It cleaves the heme ring at the alpha-methene bridge to form biliverdin, which is converted to bilirubin by biliverdin reductase. The carbon monoxide released from heme oxygenase reactions has also been shown to influence vascular tone and the function of nitric oxide synthase [24].

Several studies have also indicated that the ability to upregulate HO-1 expression is an important protective factor in many diseases such as cardiovascular disease, renal transplantation, and necrotizing enterocolitis [25]. Our research is focused on following-up with one specific clinical application-enteral SPH powder in the treatment of the neonatal intestinal inflammatory disease and necrotizing enterocolitis (NEC). HO-1 deficiency has been shown to lead to increased NEC development, while HO-1 induction increased Treg/Teff ratios and prevented NEC development in animal models [26].

\section{ALOX12 gene down regulation}

Metabolic syndrome is a term used when the clustering of at least three of five of the following medical conditions occurs: abdominal (central) obesity, elevated blood pressure, elevated fasting plasma glucose (or overt diabetes), high serum triglycerides, and low high-density lipoprotein (HDL) levels.

ALOX12, a lipoxygenase-type enzyme, is encoded by the ALOX12 gene and is characterized by its ability to metabolize AA into 15(S)-HETE, a hormone-like autocrine and paracrine signaling agent, involved in the inflammation response and metabolic syndrome. Elevated ALOX12 levels have been implicated in type 1 diabetes, in the fat cells of white adipose tissue of obese diabetic 
patients and in excessive production of reactive oxygen species and inflammation [27]. As a result, down-regulation of ALOX12 and its metabolite(s) by SPH may contribute to the retardation of obesity, diabetes, hypertension, and/or metabolic syndrome.

\section{CONCLUSION}

It may be concluded from our results that salmon protein hydrolysate powder contains bioactive peptides that can up/down regulate certain oxidative protective genes in human epithelial cells. The unusually high number of genes shown to be impacted may be a direct result of the over 250 peptides of molecular weights between 1500 to 20,000 Dalton that are present in the test article, that could act as gene modulators. The upregulation in the HMOX1 gene, particularly in intestinal epithelial cells, could be the first step to developing a food based anti-inflammatory powder to help stabilize GI tissue damage via up-regulation of the HO-1 specific anti-oxidative enzyme in the GI tract. A follow-up study with enteral SPH treatment in the NEC animal model is under consideration.

List of Abbreviations: SPH, salmon protein hydrolysate; FTH1, Ferritin transferase (heavy subunit) 1; HMOX1, hemo-oxygenase 1; ALOX12, arachidonate 12-lipoxygenase; NQO1, $\mathrm{NADP}(\mathrm{H})$ :quinine oxidoreductase; GCLC, glutamyl cysteine ligase; UGT, UDPglucuronosyltransferase; ROS, reactive oxygen species, NEC, necrotizing enterocolitis.

Competing Interests: Bomi Framroze is a consulting scientist for Hofseth Biocare AS.

Author's Contributions: Bomi Framroze designed the research, wrote the manuscript and had primary responsibility for the final content. Freddy Havaldar and Shashi Misal conducted the research. All authors read approved the final version of the manuscript.

Acknowledgments and Funding: The research was funded by a grant from Hofseth Biocare AS to Freddy Havaldar and St. Xaviers College. (HBC-0120).

\section{REFERENCES}

1. Ward JF: The complexity of DNA damage: relevance to biological consequences. Int. J. Radiat Biol 1994, 66: 427-432.

2. Goetz ME, Luch A: Reactive species: A cell damaging rout assisting to chemical carcinogens. Cancer Lett 2008, 266: 73-83.

3. Strassburg, CP, Manns MP, Tukey RH: Differential Down-Regulation of the UDPGlucuronosyltransferase 1A Locus Is an Early Event in Human Liver and Biliary Cancer. Cancer Res 1997, 57: 2979-2985.

4. Dhakshinamoorthy S, Long DJ, Jaiswal AK: Antioxidant Regulation of Genes Encoding Enzymes That Detoxify Xenobiotics and Carcinogens. Curr. Top Cell Regul 2000, 36: 201-216.

5. Jaiswal AK: Regulation of genes encoding $\mathrm{NAD}(\mathrm{P}) \mathrm{H}$ :quinone oxidoreductases. Free Radic Biol Med 2000, 29: 254-262. 
6. Auten RL, O'Reilly MA, Oury, TD, Nozik-Grayck E, Whorton MH: Transgenic extracellular superoxide dismutase protects postnatal alveolar epithelial proliferation and development during hyperoxia. Am J Physiol Lung Cell Mol Physiol 2006, 290: L3240.

7. Ho YS, Xiong Y, Ma W, Spector A, Ho DS: Mice lacking catalase develop normally but show differential sensitivity to oxidant tissue injury. J Biol Chem 2004, 279: 3280432812.

8. Koo HC, Davis JM, Li Y, Hatzis D, Opsimos H, Pollack S, Strayer MS, et al.: Effects of transgene expression of superoxide dismutase and glutathione peroxidase on pulmonary epithelial cell growth in hyperoxia. Am J Physiol Lung Cell Mol Physiol 2005, 288: L718-726.

9. Talalay P, Holtzclaw WD, Winkova-Kostova AT: Importance of Phase 2 gene regulation in protection against electrophile and reactive oxygen toxicity and carcinogensis. Adv Enzyme Regul 2004, 44: 335-367.

10. Yu X, Kensler T: Nrf2 as a target for cancer chemoprevention. Mutat Res 2005, 591: 93102.

11. Itoh K, Wakabayashi N, Katoh Y, Ishii T, Igarashi K, Engel JD, Yamamoto M: Keap1 represses nuclear activation of antioxidant responsive elements by Nrf2 through binding to the amino-terminal Neh2 domain. Genes Dev 1999, 13: 76-86.

12. Venugopal R, Jaiswal AK: Nrf2 and Nrf1 in association with Jun proteins regulate antioxidant response element-mediated expression and coordinated induction of genes encoding detoxifying enzymes. Oncogene 1998, 17: 3145-3156.

13. Marini MG, Chan K, Casula L, Kan YW, Cao A, Moi P: hMAF, a Small Human Transcription Factor That Heterodimerizes Specifically with Nrf1 and Nrf2. J Biol Chem 1997, 272: 16490-16497.

14. Nguyen T, Sherratt PJ, Pickett, C. B. Regulatory mechanisms controlling gene expression mediated by the antioxidant response element. Annu Rev Pharmacol Toxicol 2003, 43, 233-260.

15. Pierrou S, Broberg P, O’Donnell RA, Pawłowski K, Virtala R, Lindqvist E: Expression of Genes Involved in Oxidative Stress Responses in Airway Epithelial Cells of Smokers with Chronic Obstructive Pulmonary Disease. American Journal of Respiratory and Critical Care Medicine 2007, 175(6): 577-587.

16. Joyce NC, Harris DL, Zhu CC: Age-Related Gene Response of Human Corneal Endothelium to Oxidative Stress and DNA Damage. Cornea 2011, 52(3): 1641-1649.

17. Crujeiras A, Parra D, Milagro F, Goyenechea E, Larrarte E, Margareto J, Martinez A: Differential Expression of Oxidative Stress and Inflammation Related Genes in Peripheral Blood Mononuclear Cells in Response to a Low-Calorie Diet: A Nutrigenomics Study. OMICS: A Journal of Integrative Biology 2008, 12(4): 1-12 
18. Chao G, Wang Y, Zhang S: Colonic mucosal gene expression in irritable bowel syndrome rats by the liquid chip technology. Int J Clin Exp Pathol 2016, 9(10): 1075110755.

19. Berberat P, Rahim Y, Yamashita K, Warny M, Csizmadia E, Robson S, Bach F: Heme oxygenase-1-generated biliverdin ameliorates experimentalmurine colitis. Inflamm Bowel Dis 2005, 11(4): 350-359

20. Blanchard R, Moore J, Green C, Cousins R: Modulation of intestinal gene expression by dietary zinc status: Effectiveness of cDNA arrays for expression profiling of a single nutrient deficiency. PNAS 2001, 98(24): 13507-13513

21. Imam M, Ismail M, Ithnin H, Tubesha Z, Omar A: Effects of Germinated Brown Rice and Its Bioactive Compounds on the Expression of the Peroxisome ProliferatorActivated Receptor Gamma Gene. Nutrients 2013, 5(2): 468-477

22. Orino K, Lehman L, Tsuji Y, Ayaki H, Torti S, Torti F: Ferritin and the response to oxidative stress. Biochemical Journal 2001: 357(1), 241-247.

23. Framroze B, Vekariya S, Swaroop D: A Placebo-Controlled Study of the Impact of Dietary Salmon Protein Hydrolysate Supplementation in Increasing Ferritin and Hemoglobin Levels in Iron-Deficient Anemic Subjects. Journal of Nutrition and Food Sci 2015, 5(4): 379-382.

24. Siow RCM, Sato H, Mann G: Heme oxygenase-carbon monoxide signalling pathway in atherosclerosis: anti-atherogenic actions of bilirubin and carbon monoxide. Cardiovascular Research 1999, 41(2): 385-394.

25. Otterbein LE, Soares MP, Yamashita K, Bach FH: Heme oxygenase-1: unleashing the protective properties of heme. Trends in Immunology 2003, 24(8), 449-455.

26. Schulz S, Chisholm KM, Zhao H, Kalish F, Yang Y, Wong RJ, Stevenson DK: Heme oxygenase- 1 confers protection and alters $\mathrm{T}$-cell populations in a mouse model of neonatal intestinal inflammation. Pediatr Res 2015, 77(5): 640-648

27. Kuhn H, Banthiya S, Van Leyen K: Mammalian lipoxygenases and their biological relevance. Biochimica et Biophysica Acta (BBA) - Molecular and Cell Biology of Lipids 2015: 1851(4), 308-330. 